\title{
Risk-Based Approach for Improving Concrete Bridges' Inspection Planning
}

\author{
Sindre Tronsli, Samindi M.K Samarakoon and R.M Chandima Ratnayake \\ Department of Mechanical and Structural Engineering and Materials Science, University of \\ Stavanger, Norway, www.uis.no
}

\begin{abstract}
Visual inspection forms the basis of the inspection planning process for concrete bridges. The authority responsible for bridge inspection maintains a database to record past inspection results, in order to plan future inspections. It is a challenge to recognize and classify bridges that it is essential to inspect based on inherent requirements. This is further exacerbated by the limited budget available. This manuscript describes a methodology for classifying bridges based on risk of potential failure and distributing the annual inspection budget for carrying out inspections on bridges accordingly. The absence of such a methodology allocation of resources for bridge inspection without real need. For example, on some occasions it is not necessary to inspect certain bridges on a time basis. Hence, this study focuses on developing an inspection-planning approach based on the actual and predicted condition (i.e. based on the database of past inspection data). It enables the bridges to be classified into different categories, based on the risk of potential failures. This enables the effective distribution of annual budgets among the bridges, avoiding unnecessary inspection that incurs pointless inspection costs.
\end{abstract}

Keywords: Visual Inspection, Concrete Bridges, Group Technology.

\section{Introduction}

Routine bridge inspections are essential for maintaining information, damage status and proper prioritization of bridge maintenance measures. In the Norwegian Public Road Administration (NPRA), bridge inspections are defined as follows: "Inspection is a visual control combined with surveying and testing of materials carried out to assess the bridges' condition and level of safety. The inspection shall reveal the need for operational measures and/or maintenance, as well as any need for reinforcement or rebuilding" (Vegdirektoratet, 2000). According to the available information on bridge maintenance and current inspection procedure at the NPRA, visual inspection has not been performed annually for over half the bridges in Norway. These are serious figures, highlighting troublesome issues with the Road Administration Inspection System. Following the disclosures, the NPRA estimated in 2017 that there is a lag in maintenance and improvements for bridges and quays, which has a cost of NOK 15 billion (Statens Vegvesen, 2017a). From 2017, the government increased funding for road and bridge maintenance in the national budget by NOK 2.9 billion, which corresponds to an increase of 7.7\% (Regjeringen, 2017). But, even though the government has increased its support for bridge maintenance in recent years, it is not certain that this support will persist. The NPRA estimates that they have a huge backlog of NOK 15 billion in the maintenance of bridges and quays. At the same time, in 2013, an ambitious streamlining programme was established, which states that the NPRA must cut internal costs by $10-15 \%$ by 2023 . This corresponds to cuts of around 
NOK 1.4 billion (Statens Vegvesen, 2018). Therefore, it is vital to improve the existing inspection procedure, to optimize the available budget. This situation underlines the need for Risk Based Inspection procedures, which include optimal prioritization of inspections and the determination of optimal inspection interval. This paper proposes the use of Risk Based Inspection (RBI) for the planning of inspections, which will help to optimize and increase the efficiency of the inspection procedure carried out by the NPRA.

\section{The Existing Inspection Procedure in NPRA}

In the inspection programme, once a bridge needs to be inspected, visual inspection, combined with non-destructive/destructive testing, is performed to assess the condition and safety of the bridge. Then, any damage or deficiencies in the bridge's structural members (i.e. location) should be recorded in a database. Possible damage/deficiencies (i.e. corrosion, cracks, spalling, discolouring, etc.) in bridges are listed in the NPRA handbook (Vegdirektoratet, 2000) with a representing number. Moreover, the NPRA has established a bridge management system called 'Brutus' to input all the information about all bridges in Norway. Therefore, the Brutus (i.e. bridge inspection data base - BIDB) consists of the historical inspection data of the bridges. When assessing damage, it is vital to classify the type, level (use Table 1), cause and consequences of the damage to the entire bridge and/or the environment (use Tables 2 and 3). Then, to recommend the level of action required, a priority level is calculated using Equation (1). Furthermore, a higher priority level indicates a requirement for immediate action/measure

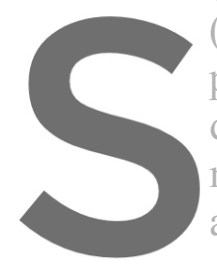
(Ratnayake and Samara parameters set by the damage level for spalling/Reinforcement (RF) not been set. This study will therefore devel accordingly.
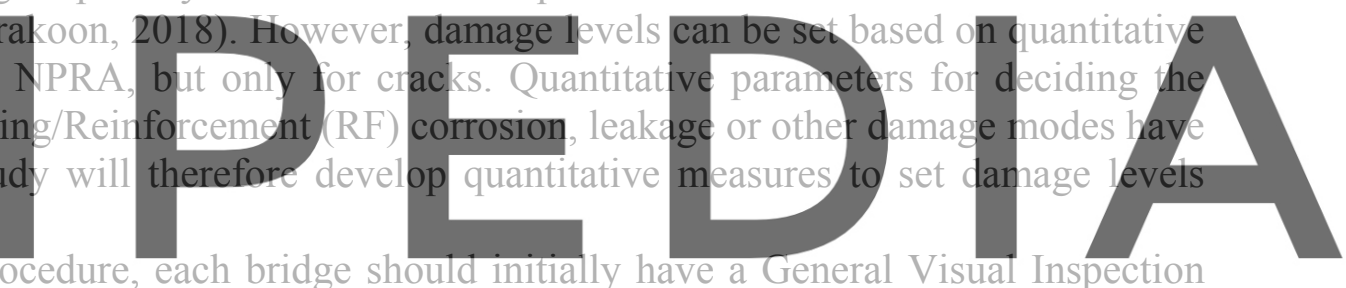

According to the procedure, each bridge should initially have a General Visual Inspection (GVI) every year. Each bridge will. initially have to carry out a Close Visual. Inspection (CVI)

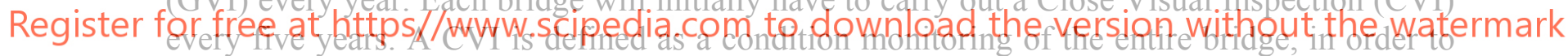

verify that it fulfils its function, and is a more comprehensive type of inspection compared to a GVI. But the intervais of one and five years for GVI and CVI, respectively, do not always represent the optimal inspection interval. The procedure for changing the inspection interval starts with observation of serious damage during inspection, with the consequence level being set to a minimum of 3 . Then, the inspection engineer evaluates the damage and the bridge as a whole, in respect of whether the inspection interval should be changed for that particular bridge. If the result of the evaluation indicates that the inspection interval should be changed, a Risk and Vulnerability Assessment (RVA) shall be carried out to determine a new inspection interval (Vegdirektoratet, 2018).

Table 1. Damage/defect level and rank. (Vegdirektoratet, 2000)

\begin{tabular}{|l|l|l|}
\hline Rank & Damage/deficiency level \\
\hline 1 & Low (L) & \\
\hline 2 & Medium (M) & \\
\hline 3 & High (H) & \\
\hline 4 & Very high (VH) & \\
\hline
\end{tabular}


Sindre Tronsli, Samindi M.K Samarakoon and R.M Chandima Ratnayake

Table 2. Consequence type and level. (Vegdirektoratet, 2000)

\begin{tabular}{|l|r|}
\hline Consequence type & *Abb. \\
\hline $\begin{array}{l}\text { Damage/defect(s) threatening } \\
\text { bearing capacity }\end{array}$ & $\mathrm{B}$ \\
\hline $\begin{array}{l}\text { Damage/defect(s) threatening } \\
\text { road safety }\end{array}$ & $\mathrm{RS}$ \\
\hline $\begin{array}{l}\text { Damage/defect(s) that may } \\
\text { increase maintenance costs }\end{array}$ & $\mathrm{E} / \mathrm{A}$ \\
\hline $\begin{array}{l}\text { Damage/defect(s) that may } \\
\text { affect the environment/ } \\
\text { aesthetics }\end{array}$
\end{tabular}

\begin{tabular}{|c|l|c|}
\hline $\begin{array}{c}\text { Consequence } \\
\text { Level }\end{array}$ & \multicolumn{1}{|c|}{ Measures to be taken } & Rank \\
\hline $\mathrm{L}$ & No action required & 1 \\
\hline $\mathrm{M}$ & $\begin{array}{l}\text { Register the recommended measures } \\
\text { in BIDB }\end{array}$ & 2 \\
\hline $\mathrm{H}$ & $\begin{array}{l}\text { - Register the recommended } \\
\text { measures in BIDB, and interval shall be } \\
\text { - Inspection } \\
\text { recommended }\end{array}$ & 3 \\
\hline $\mathrm{VH}$ & Immediate action is required & 4 \\
\hline
\end{tabular}

*Abbreviation - B: Bearing capacity; RS: Road safety; M/R: Maintenance/Repair; E/A: Environment and aesthetic appearance

Table 3. Example: Damage/defect level and rank -crack width (CW). (Vegdirektoratet, 2000)

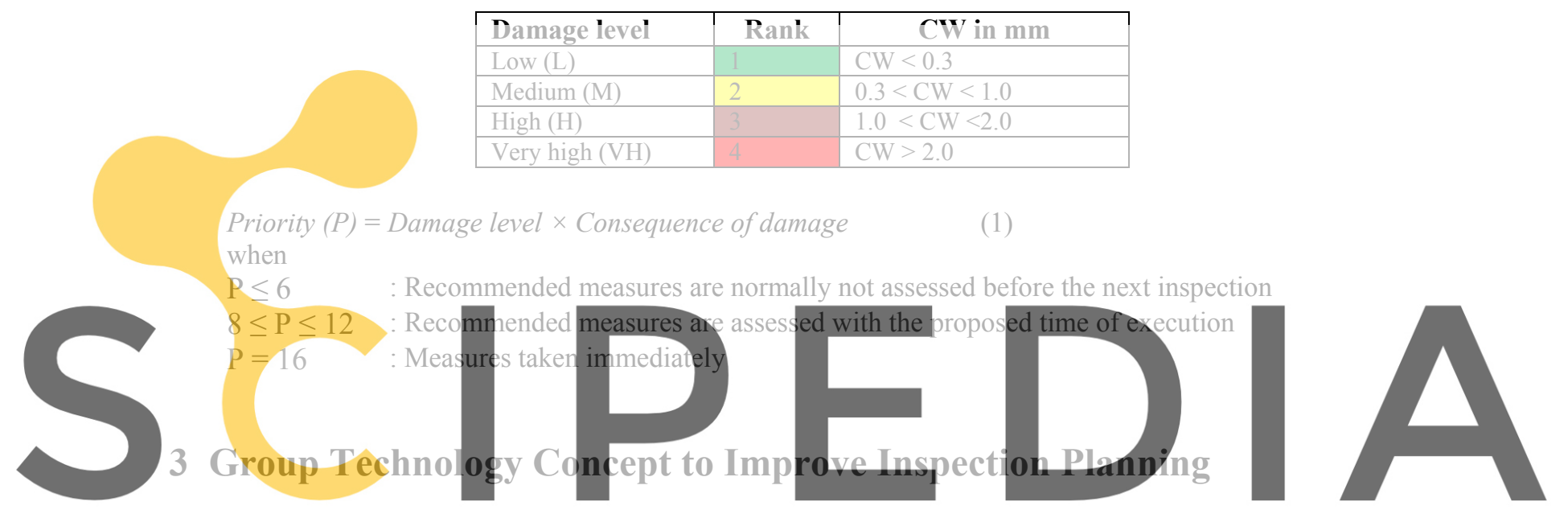

\subsection{Bridge Families and Representative Bridges}

Register for free at https//www.scipedia.com to download the version without the watermark in order to develop optimal inspection procedures, the concept of group technology has been used, as it has the potential to increase the efficiency of the inspection procedure (Rachman and Ratnayake, 2019). Group technology is widely used in the manufacturing industry to classify the system into subsystems and subdivide them into part families, based on design attributes and manufacturing similarities. According to the literature, the use of group technology in manufacturing processes helps to both improve the productivity and increase the efficiency of the process. However, there are limited applications of the concept in civil engineering applications. Group technology concepts are based on creating families of bridges with similar characteristics, such as building materials, degradation mechanisms and condition, and, for each bridge family, a representative bridge is designated. The representative bridge should have all the characteristics of the remaining bridges in each bridge family. The purpose of the representative bridges is that, on the basis of thorough inspections of the representative bridge, one should be able to predict future damage conditions on the remaining bridges in the bridge family. The representative bridge must undergo frequent inspections, and one should have good information about its condition. This information is used to map and predict the condition of the remaining bridges in the bridge family and should significantly reduce the number of GVIs needed. 
Initially, based on building material, the bridges are grouped into primary families: reinforced concrete, pre-stressed concrete and steel. The secondary families group the bridges primarily by location and exposure. For example, they can be grouped as bridges close to the sea, inland bridges and high-risk bridges which need special attention. To classify the groups, information from the BIDB about previous inspections is used. Furthermore, a secondary family consisting of "high-risk bridges" includes bridges in poor condition and operates independently of exposure zone. The requirement for bridges in the high-risk family is a priority level $>9$ on critical damage, as given in Equation (1), i.e. damage priority 12 or 16. Critical damage is damage with the highest priority level on the actual bridge. Bridges in the "High-risk" family will not have a representative bridge, because all the bridges in the bridge family are at high risk and therefore need thorough and frequent inspections on the same basis as the representative bridges. The different secondary families are as follows: bridges in coastal climates with priority level $\leq 9$ on critical damage, bridges in inland climate with priority level $\leq 9$ on critical damage, bridges with priority level $>9$ on critical damage.

The study uses the bridges in the Rogaland, Norway, area to illustrate the method. Rogaland consists of 721 road bridges; concrete is the most typical building material, with 522 bridges. Furthermore, 133 bridges are built with pre-stressed concrete and 66 bridges with steel. Moreover, Rogaland is a region in Norway with an elongated coast, and this is evidenced by the high number of bridges located near/within the coastal area. In total, 359 of Rogaland's 720 bridges are in coastal areas, of which 48 qualify for the secondary family, "high-risk bridges". That leaves 311 bridges in the secondary family "bridges in coastal climate". Although Rogaland has an elonga 361 bridges are located risk bridges". That leaves 3.2 Selection of Representative Bridge
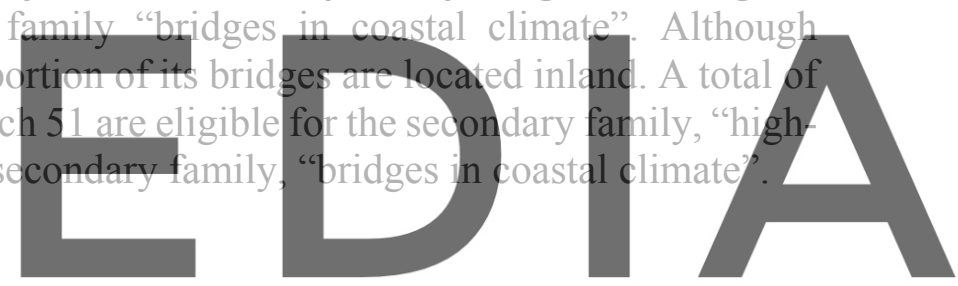

The representative bridges should have all the damage features (i.e. corrosion, leakage, spalling,

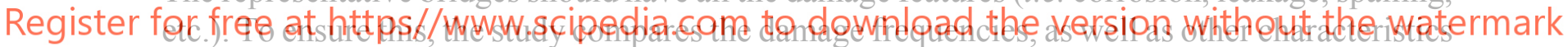

like age, length and structural integrity for the individual bridges to the bridge family as a whole.

This is information that is available in NPRA's database, Brutus. The study therefore involves a damage frequency analysis, and this is the decisive factor when appointing representative bridges. For this analysis, 90 bridges have been used, and the bridges are grouped. Then, damage vs frequency analysis has been carried out for each group which consists of at least 10 bridges. Figure 1 shows a Pareto chart of damage vs frequency for the reinforced concrete bridges in coastal areas, based on the registered inspections in the BIDB database until 2018. The dominant mechanisms of damage to reinforced concrete bridges in coastal areas is found to be corrosion of reinforcement and spalling (spalling/RF corrosion), leakage and cracks $(80 \%)$. Based on the frequency of each type of damage, representative bridges have been assigned for each bridge group. For example, based on the damage and frequency analysis of reinforced concrete bridges in coastal areas, "Kongsbrua" has been chosen as the representative bridge for reinforced concrete bridges in coastal climate in Rogaland, Norway. It represents the remaining bridges, with an approximately equal frequency of damage to the rest of the bridging family, with damage rates of $45 \%, 27 \%$ and $27 \%$ for spalling/RF corrosion, leakage and cracks, respectively. An assessment of other characteristics like age, length and structural integrity also 
has to be a significant factor in the process. In other words, the representative bridge should have similarities to the rest of the bridge family when it comes to damage frequencies, age, length and structural integrity.

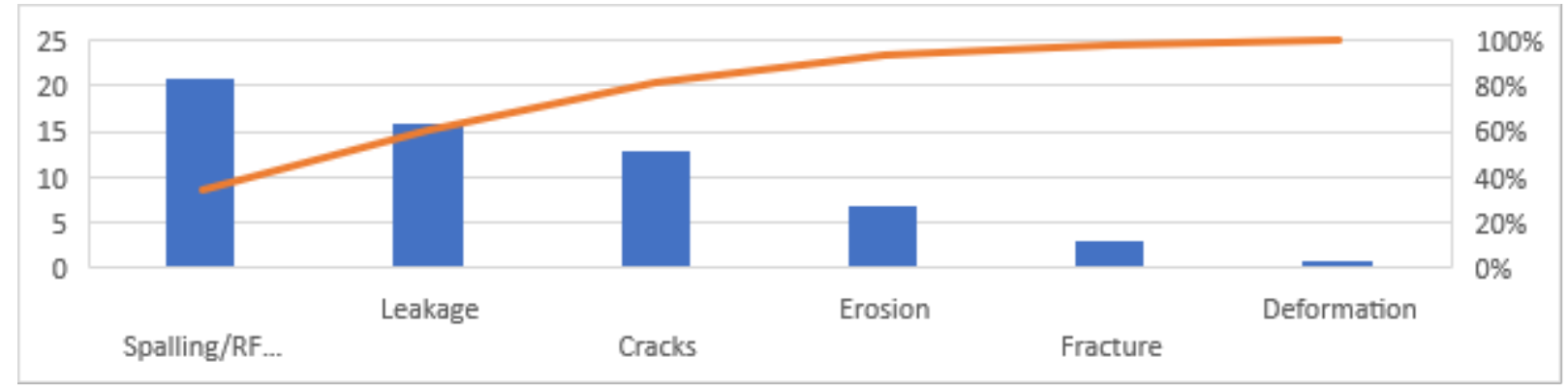

Figure 1. Different types of damage vs frequency in bridge group: reinforced concrete bridges in coastal areas.

The methodology based on the concept of group technology has great potential in inspection planning, and the use of representative bridges can significantly reduce the number of GVIs, without compromising safety. But there are several factors that determine the credibility of the method. Firstly, the bridges in the different families must be of a similar nature. This includes approximately similar damage frequencies, as well as similar characteristics like age, length and structural integrity. Secondly, the appointment of the representative bridge must be as

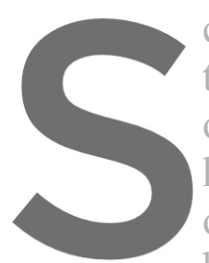
the representative bridg of the bridges in the fan high-risk families. This is because bridges in th other in terms of climate, age and length. The on building material is one or more cases of serious damage (priority $\geq 12$ ). It would be wrong to designate representative bridges for the high-risk families, as it is very difficult to predict future

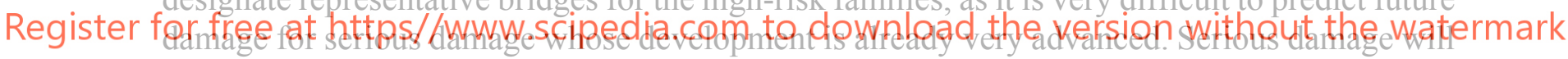
often develop in an accelerating and unpredictable way, making the prediction of future condition uncertain (Vegdirektoratet, 2000). Therefore, all bridges in the high-risk families should be given priority, with frequent and thorough GVIs, on the same basis as the representative bridges. For bridges in families with a representative bridge, simple inspections can be given a lower priority, as long as inspections of the representative bridge have given satisfactory results.

\subsection{Comparison of Repair Cost}

In order to understand the severity of the damage in terms of repair costs, the cost of implemented measures in the most typical damage modes - crack, spalling/RF corrosion and leakage - have been studied. This was done by using the BIDB database, where both damage priority number (i.e. calculated as given in Equation (1)) and estimation of repair cost related to the damage have been recorded. The correlation between damage, damage priority number and cost of repair has been studied, to understand which damage should be prioritized in maintenance and inspection, from a cost-based perspective (Tronsli, 2019). It could be seen that spalling/RF corrosion is the most expensive to repair, followed by cracks and leakage. For 
spalling/corrosion, the repair costs will, to a large extent, increase with increasing priority, compared to cracks and leakage. Therefore, from a cost-based perspective, it is beneficial to repair spalling/RF corrosion at an early phase of damage development.

\subsection{Modification of the Existing Inspection Planning Process}

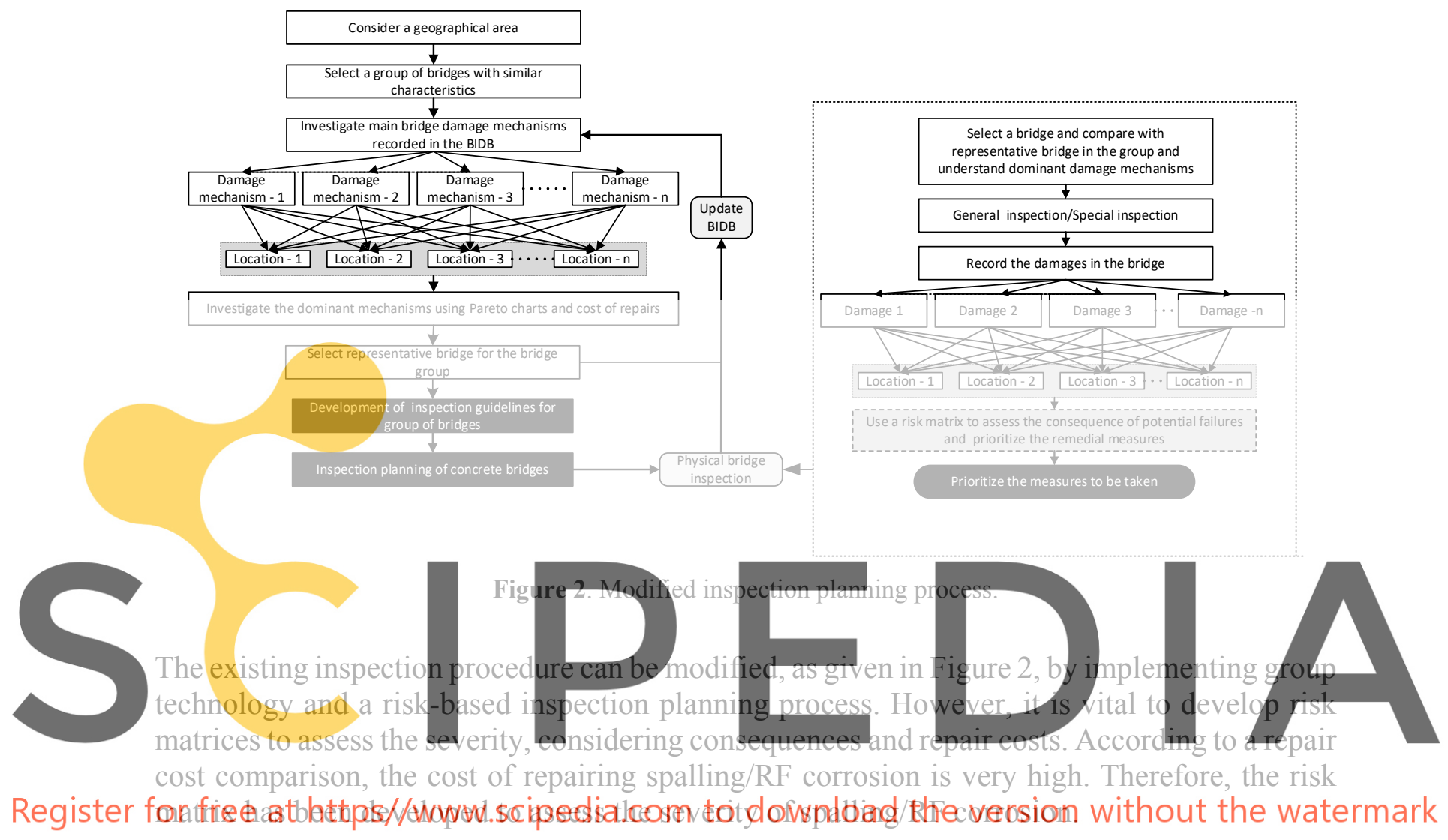

\section{Development of Risk Matrix}

To aid the inspection planning and to ensure an optimal inspection interval, the study developed risk matrices, which decide optimal interval time, based on the priority level (refer to Equation (1)) of the critical damage. The risk matrices developed are only in respect of the damage mode, spalling/RF corrosion, as the damage frequency analysis and cost analysis showed that spalling/RF corrosion are the most dominant and expensive of the damage modes. However, the method of developing risk matrices is applicable for other damage modes. Four matrices are applicable for the damage mode, spalling/RF corrosion, and they are based on the different consequence types the NPRA uses (bearing capacity, road safety, maintenance and aesthetics) when assessing damage. Table 4 shows the risk matrix developed for consequence type, "maintenance". In order to correctly assess the level of spalling/RF corrosion damage, the study also developed a new scale, which evaluates the damage based on quantitative parameters. It assesses the damage level, based on the size of the area of damaged concrete, and is only applicable for reinforced and pre-stressed concrete bridges. The scale for consequence level is used as in the existing procedure. The exception is for the consequence type, "maintenance", 
where the consequence scale is replaced with a new scale, based on estimated cost for maintenance, worked out from the cost analysis. By adding quantitative parameters to the determination of damage and consequence levels, the accuracy of the assessment is increased, minimizing the possibility of human error or incompetence when assessing damage with consequence type, "maintenance".

Table 4. Risk matrix for assessing spalling/RF corrosion; consequence type: Maintenance.

\begin{tabular}{|c|c|c|c|c|c|c|}
\hline & & \multirow[b]{3}{*}{$\begin{array}{l}\text { Area of damaged } \\
\text { concrete }\end{array}$} & \multicolumn{4}{|c|}{ Consequence level for maintenance cost } \\
\hline \multirow{2}{*}{\multicolumn{2}{|c|}{ Maintenance }} & & 1 & 2 & 3 & 4 \\
\hline & & & $<10,000 \mathrm{NOK}$ & $\begin{array}{l}10,000-50,000 \\
\text { NOK }\end{array}$ & $\begin{array}{l}50,000-200,000 \\
\text { NOK }\end{array}$ & $\begin{array}{l}>200,000 \\
\text { NOK }\end{array}$ \\
\hline \multirow{4}{*}{$\begin{array}{c}\text { Damage } \\
\text { level / } \\
\text { measure of } \\
\text { probability } \\
\text { of failure }\end{array}$} & 1 & Under $\mathrm{Im}^{2}$ & 1 & 2 & 3 & 4 \\
\hline & 2 & $1 m^{2}-5 m^{2}$ & 2 & 4 & 6 & 8 \\
\hline & 3 & $5 m^{2}-20 m^{2}$ & 3 & 6 & 9 & 12 \\
\hline & 4 & Over $20 \mathrm{~m}^{2}$ & 4 & 8 & 12 & 16 \\
\hline
\end{tabular}
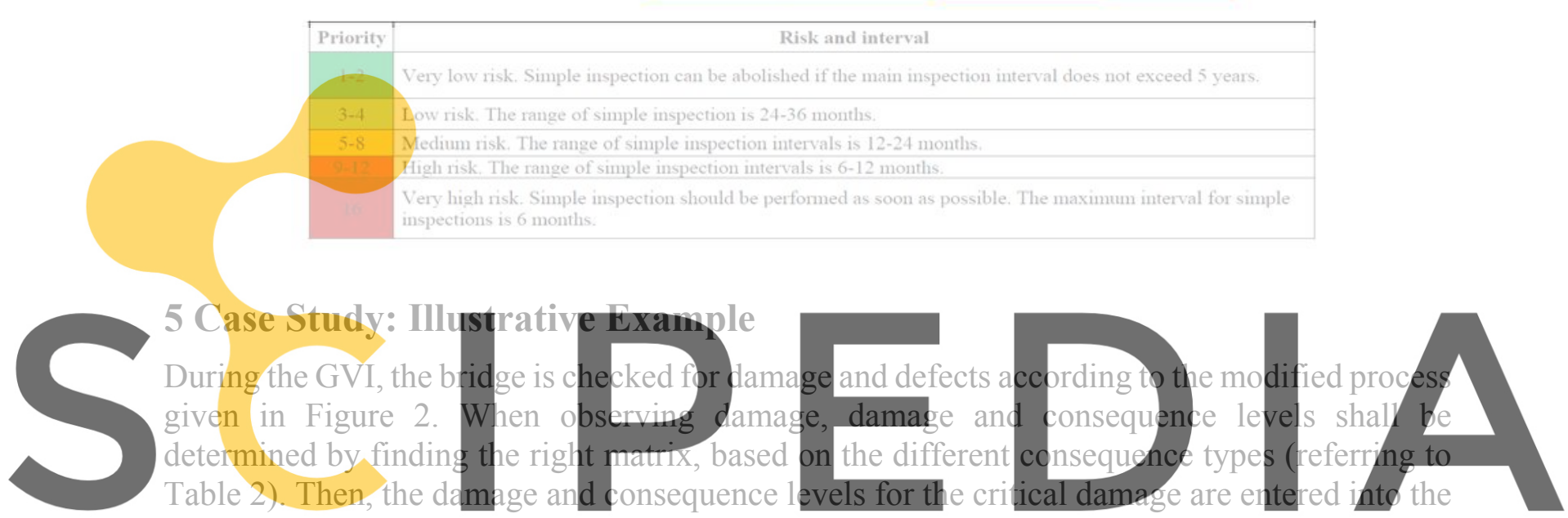

risk matrix, and the matrix will propose a new inspection interval for future GVIs on that

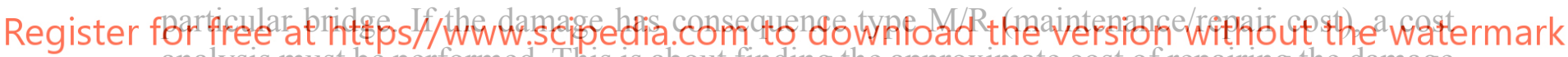
analysis must be performed. This is about finding the approximate cost of repairing the damage and must be done to find the consequence level, in order to find favourable inspection intervals

for GVIs. Bridge 11-0307 Gyastøl, which is located in Rogaland, Norway, has been chosen. Built in 1945, it is a reinforced concrete bridge located in a coastal area. "Gyastøl" is compared with "Kongsbrua", which is the representative bridge for reinforced concrete bridges in coastal areas. Based on the representative bridge, critical damage to "Gyastøl" is spalling/RF corrosion on the bottom of the bridge slab, and the damage has been recorded with consequence level 2 and consequence type "maintenance". The damage description states that there is around $1.5 \mathrm{~m}^{2}$ of spalling, as given in Table 5, which corresponds to damage level 2. Using Table 4, a new inspection interval for future GVIs on the bridge can be estimated. The analysis shows that there is a low risk of failure, valued with priority 4 and consequence type "maintenance", and the matrix suggests a new inspection interval for upcoming GVIs of 24-36 months. Since the previous GVI on the bridge was carried out on 6.6.2018, the next GVI will be set to the period 6.6.2020-6.6.2021. The case shows that it is possible to increase the intervals of GVI using risk analysis and the risk matrix. This will ensure an optimal allocation of resources. Furthermore, this increase in efficiency will enable an increase in resources dedicated to those bridges with the greatest need for frequent inspections. 
Sindre Tronsli, Samindi M.K Samarakoon and R.M Chandima Ratnayake

Table 5. Inspection registered in BIDB: Bridge 11-0307 Gyastøl.

\begin{tabular}{|c|c|c|c|c|c|c|c|c|}
\hline \multicolumn{9}{|c|}{ Inspection } \\
\hline \multicolumn{9}{|c|}{ Close visual inspection 12.09.2019 (Done) } \\
\hline \multirow{2}{*}{\multicolumn{4}{|c|}{$\begin{array}{l}\text { Damage mode } \\
\text { Spalling/RF corrosion }\end{array}$}} & \multicolumn{5}{|l|}{ Status } \\
\hline & & & & Open & & & & \\
\hline \multicolumn{4}{|c|}{ Damage level } & \multicolumn{5}{|c|}{ Consequence level } \\
\hline 1 & 2 & 3 & 4 & Bearing capacity & 1 & 2 & 3 & 4 \\
\hline \multirow{2}{*}{\multicolumn{4}{|c|}{$\begin{array}{l}\text { Cause of damage } \\
\text { Normal degradation of concrete }\end{array}$}} & Traffic safety & 1 & 2 & 3 & 4 \\
\hline & & & & Maintenance & 1 & 2 & 3 & 4 \\
\hline \multicolumn{4}{|c|}{ Damage description } & Aesthetics & 1 & 2 & 3 & 4 \\
\hline
\end{tabular}

\section{Discussion and Conclusions}

The existing NPRA inspection procedure shows how bridges in Norway prioritize inspections and utilize their budgets. It can be seen that the current inspection procedure does not utilize the allocated inspection budget efficiently. To improve the existing method, and to increase the efficiency of both the inspection procedure and the resource allocation in the NPRA, the concept of group technology is proposed. The proposal to group the bridges into families, according to different properties, and then to designate representative bridges for each bridge family is a new way of working that will increase both efficiency and safety. However, it must be considered that the sample size chosen in this study is small. Therefore, it is vital to carry out further work and a damage frequency analysis using a larger sample size of bridges. However, the application of the proposed improvements can contribute to a reduction in the number of simple inspections, without compromising on safety
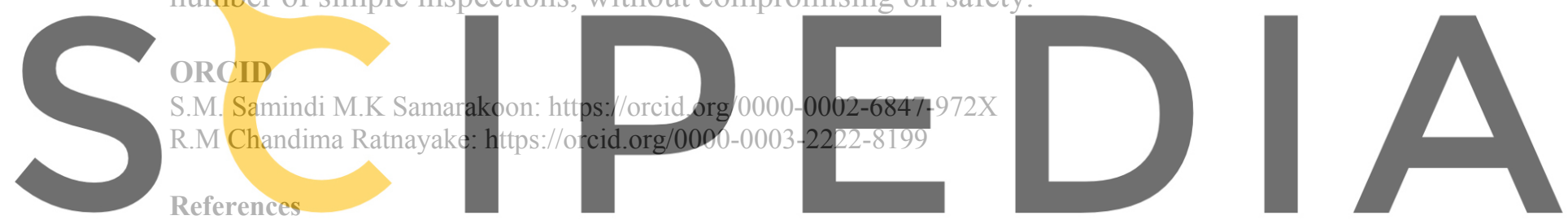

Rachman, A.Y. and Ratnayake, R.M.C. (2019). Corrosion loop development of oil and gas piping system based

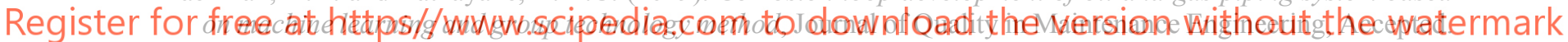

Ratnayake, R.M.C. and Samarakoon, S.M.S.M.K. (2018). Risk based inspection planning methodology for concrete bridges. I: Proceedings of the International Conference on Sustainable Materials, Systems and Structures (SMSS2019). Challenges in Design and Management of Structures, 20-22 March 2019 - Rovinj, Croatia. PRO 128, Vol. 4. RILEM Publications 2019 ISBN 978-2-35158-226-8, p. 184-191.

Regjeringen (2017). Økte bevilgninger og redusert vedlikeholdsetterslep på veinettet. Available at: https://www.regjeringen.no/no/aktuelt/okte-bevilgninger-og-redusert-vedlikeholdsetterslep-paveinettet/id2575305/.

Tronsli, S. (2019). Optimization of inspection budget allocation, Thesis, University of Stavanger, Norway.

Statens Vegvesen (2017a). Svikt $i$ bruforvaltningen skal rettes opp Statens vegvesen, Available at: https://www.vegvesen.no/om+statens+vegvesen/presse/nyheter/nasjonalt/svikt-i-bruforvaltningen-skal-rettesopp.

Statens Vegvesen (2017b). Bedre bruvedlikehold. https:/www.vegvesen.no. Available at: https://www.vegvesen.no/fag/fokusomrader/forskning+og+utvikling/pagaende-fou-program/bedrebruvedlikehold.

Statens Vegvesen (2018). Arsrapport 2017, Available at: https://www.vegvesen.no/om+statens+vegvesen/om+organisasjonen/arsrapporter/ attachment/2250466? ts= 162 ddffbea0\&fast title $=\% \mathrm{C} 3 \% 85$ rsrapport +2017 .pdf.

Vegdirektoratet (2000). Håndbok V441 Inspeksjonshåndbok for bruer, Available at: https://www.vegvesen.no/ attachment/69833/binary/964063?fast_title=H\%C3\%A5ndbok+V441+Inspeksjon sh\%C3\%A5ndbok+for+bruer+\%2836+MB\%29.pdf 